Prepared for the U.S. Department of Energy

Under Contract DE-AC05-76RL01830

\title{
MARS Flight Engineering Status
}

JE Fast, KE Dorow, SJ Morris, RC Thompson, JA Willet

November 2009

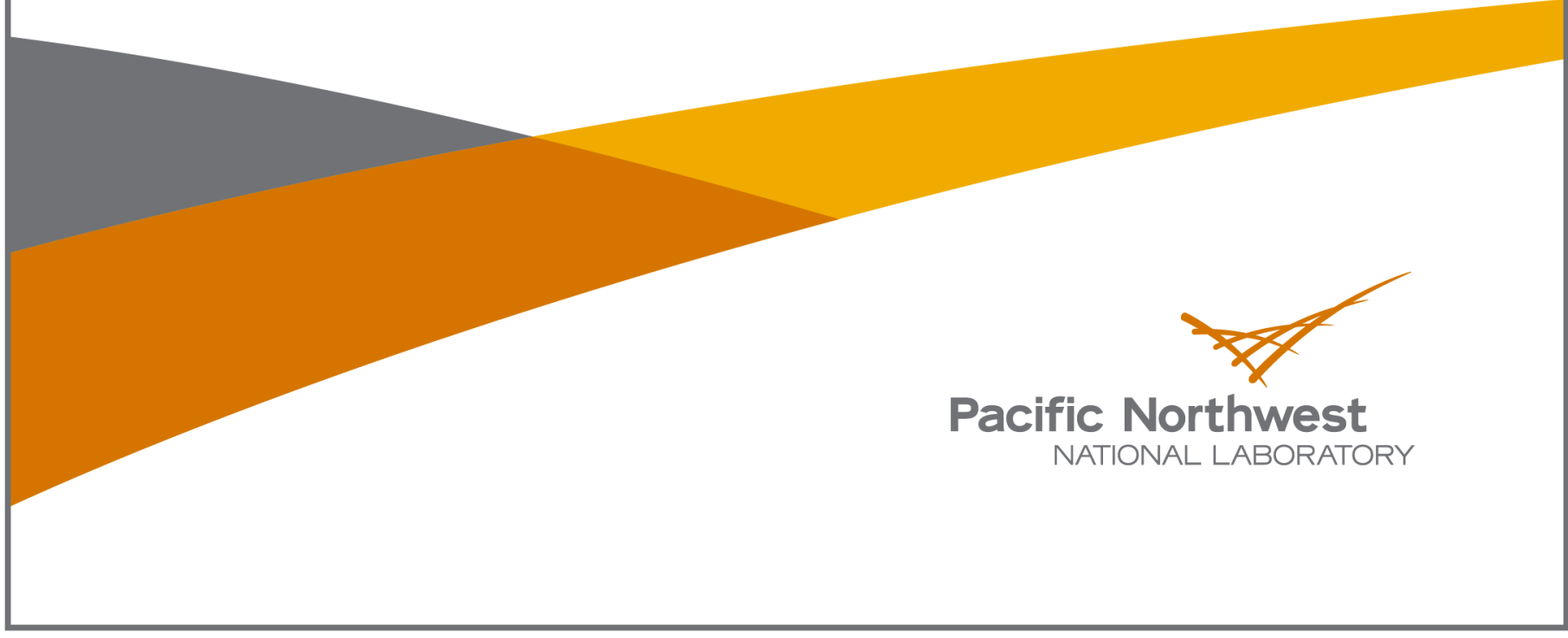




\title{
DISCLAIMER
}

This report was prepared as an account of work sponsored by an agency of the United States Government. Neither the United States Government nor any agency thereof, nor Battelle Memorial Institute, nor any of their employees, makes any warranty, express or implied, or assumes any legal liability or responsibility for the accuracy, completeness, or usefulness of any information, apparatus, product, or process disclosed, or represents that its use would not infringe privately owned rights. Reference herein to any specific commercial product, process, or service by trade name, trademark, manufacturer, or otherwise does not necessarily constitute or imply its endorsement, recommendation, or favoring by the United States Government or any agency thereof, or Battelle Memorial Institute. The views and opinions of authors expressed herein do not necessarily state or reflect those of the United States Government or any agency thereof.

\author{
PACIFIC NORTHWEST NATIONAL LABORATORY \\ operated by \\ BATTELLE \\ for the \\ UNITED STATES DEPARTMENT OF ENERGY \\ under Contract DE-AC05-76RL01830
}

Printed in the United States of America
Available to DOE and DOE contractors from the Office of Scientific and Technical Information,
P.O. Box 62, Oak Ridge, TN 37831-0062;
ph: (865) 576-8401
fax: $(865)$ 576-5728
email: reports@adonis.osti.gov

\begin{abstract}
Available to the public from the National Technical Information Service, U.S. Department of Commerce, 5285 Port Royal Rd., Springfield, VA 22161 ph: (800) 553-6847 fax: $(703) 605-6900$ email: orders@ntis.fedworld.gov online ordering: http://www.ntis.gov/ordering.htm
\end{abstract}

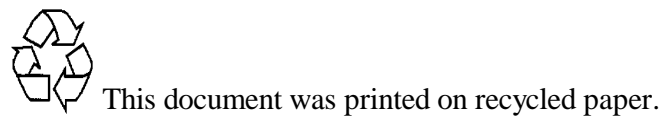




\section{MARS Flight Engineering Status}

JE Fast, KE Dorow, SJ Morris, RC Thompson, JA Willet

November 2009

Prepared for

the U.S. Department of Energy

under Contract DE-AC05-76RL01830

Pacific Northwest National Laboratory

Richland, Washington 99352 



\section{Abstract}

The Multi-sensor Airborne Radiation Survey Flight Engineering project (MARS FE) has designed a high purity germanium (HPGe) crystal array for conducting a wide range of field measurements. In addition to the HPGe detector system, a platform-specific shock and vibration isolation system and environmental housing have been designed to support demonstration activities in a maritime environment on an Unmanned Surface Vehicle (USV). This report describes the status of the equipment as of the end of FY09. 



\section{Executive Summary}

This document describes the status of the MARS Flight Engineering demonstration system. The MARS Flight Engineering project is developing a field demonstration unit as a second spiral development of the MARS Technology - a high-efficiency, compact, field-ready high purity germanium (HPGe) array. An initial laboratory prototype system was designed, built and tested under the MARS R\&D project. This second spiral includes modifications to the design based on lessons learned in the laboratory prototype, additional engineering analysis, and focus on a specific deployment platform - the SPARTAN unmanned surface vehicle (USV), a rigid hull inflatable watercraft. In addition to the HPGe detector module, the MARS Flight project is designing and building a platform-specific environmental enclosure with shock and vibration isolation for the HPGe detector unit and the electronics crate.

The field demonstration system design is complete and all of the system components, with the exception of the environmental housing, have been delivered or fabricated. Initial dry fit assembly is underway and some vacuum testing is completed. The complete HPGe system is expected to be assembled by the end of fiscal year 2009. The environmental enclosure and vibration isolation system should be available in late January, 2010 for integration tests with the SPARTAN USV. Complete system integration and testing is scheduled for February/March, continuing up to the initial demonstration activity in Charleston, SC in May 2010. 



\section{Contents}

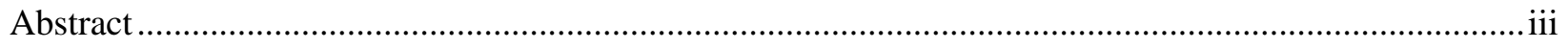

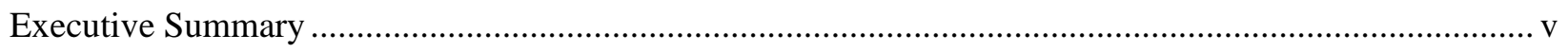

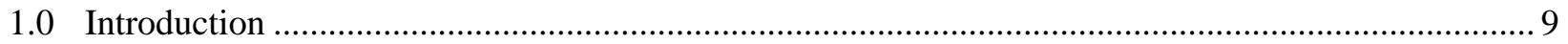

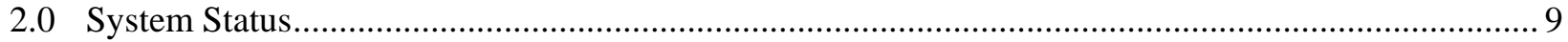

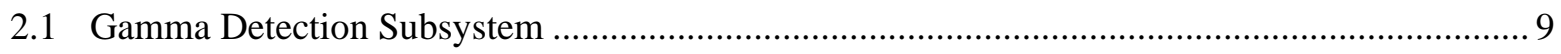

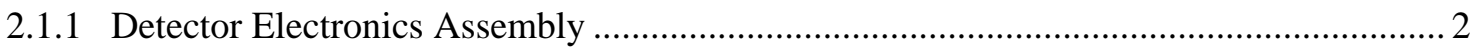

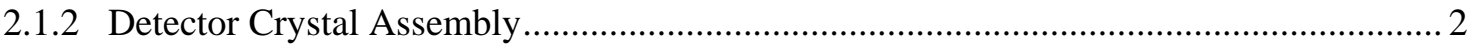

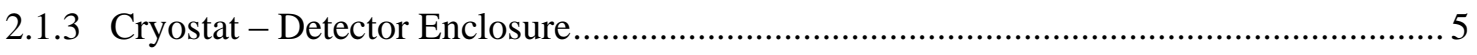

2.2 Environmental Enclosure and Vibration Isolation Subsystem ................................................ 8

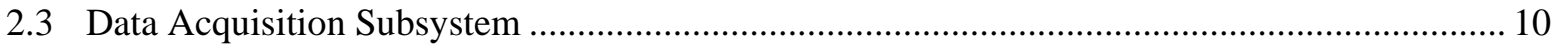

2.4 MARS Graphical User Interface (GUI) Software Module................................................... 11

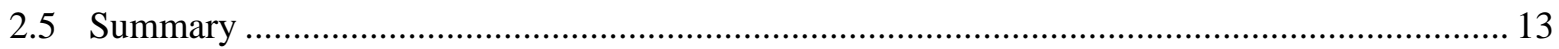




\section{Figures}

Figure 1: MARS Flight Engineering System Block Diagram.

Figure 2: Detail of Front End circuit on flex cable. Component in circular area is the FET.

Component to the below and to the right of the FET is the feedback resistor. Capacitors are built in to the circuit layout using the Kapton dielectric. The hole on the right is used to secure the flexible interconnect to the aluminum spool.

Figure 3: Front end circuit after installation of lid over FET. The lid encloses the warm $(\sim 120-$

$150 \mathrm{~K})$ FET to prevent thermal radiation from hitting adjacent HPGe detectors that need to operate at $\leq 90 \mathrm{~K}$.......

Figure 4: Spool assemblies with Kapton flexible interconnects installed................................................ 4

Figure 5: Detector Crystal Assembly mounted in Cryostat. .................................................................. 4

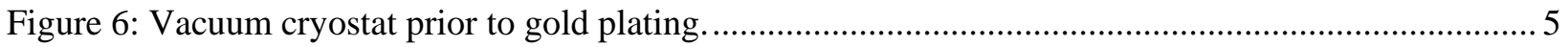

Figure 7: Liquid nitrogen Dewar. Bellows tube at top seals to top of cryostat and provides a fill port. Vertical legs are grade 5 Titanium supports that provide excellent mechanical strength with low thermal conductivity. Tank is being wired with silicon diode temperature sensors.

Figure 8: Cryostat after "Lasergold" plating. Several feedthroughs can be seen around the chamber (upper-right to lower-left): HPGe signal, high voltage, silicon diode temperature monitors, vacuum port.

Figure 9: Interior of vacuum cryostat showing Lasergold plating.

Figure 10: Thin domed window. This window is only $1 \mathrm{~mm}$ thick (aluminum) in order to maximize sensitivity to low energy gamma-rays for applications that require this sensitivity.

Figure 11: MARS vibration isolation and environmental enclosure without dome and side panels.

Figure 12: MARS system deployed in a Spartan watercraft

Figure 13: Compact PCI crate. This is the rugged crate from Dawn VME. The power supplies on the right are hot-swappable. The board next to the power supplies is the general purpose acquisition board that reads out the state-of-health data from silicon diode temperature sensors and feedback voltages from the preamplifiers. The four matching boards near the middle are the high voltage supplies for the HPGe detectors. The four matching boards towards the left are the MCA modules from XIA, Inc. The embedded processor and crate controller are located on the far left.

Figure 14: End user interface. 
PNNL-19096

\subsection{Introduction}

This document describes the status of the MARS Flight Engineering demonstration system. The MARS Flight Engineering project is developing a field demonstration unit as a second spiral development of the MARS Technology - a high-efficiency, compact, field-ready high purity germanium (HPGe) array. An initial laboratory prototype system was designed, built and tested under the MARS R\&D project. This second spiral includes modifications to the design based on lessons learned in the laboratory prototype, additional engineering analysis, and focus on a specific deployment platform - the SPARTAN unmanned surface vehicle (USV), a rigid hull inflatable watercraft. In addition to the HPGe detector module, the MARS Flight project is designing and building a platform-specific environmental enclosure with shock and vibration isolation for the HPGe detector unit and the electronics crate.

The field demonstration system design is complete and all of the system components, with the exception of the environmental housing, have been delivered or fabricated. Initial dry fit assembly is underway and some vacuum testing is completed. The complete HPGe system is expected to be assembled by the end of fiscal year 2009. The environmental enclosure and vibration isolation system should be available in late January, 2010 for integration tests with the SPARTAN USV. Complete system integration and testing is scheduled for February/March, continuing up to the initial demonstration activity in Charleston, SC in May 2010.

\subsection{System Status}

Figure 1 shows the MARS system components, as well as additional components such as neutron detectors that would form a complete Integrated Radiation Detection System. The MARS Flight Engineering project scope includes the MARS System (white boxes) plus the platform-specific enclosure, vibration isolation and graphical user interface (GUI) software for the SPARTAN demonstration ( $\tan$ boxes). Status of the various components and sub-systems is provided below.

\subsection{Gamma Detection Subsystem}

The Gamma Detection Subsystem represents the main hardware components that house the HPGe detectors and the associated analog electronics. All of these components have been delivered or fabricated. 


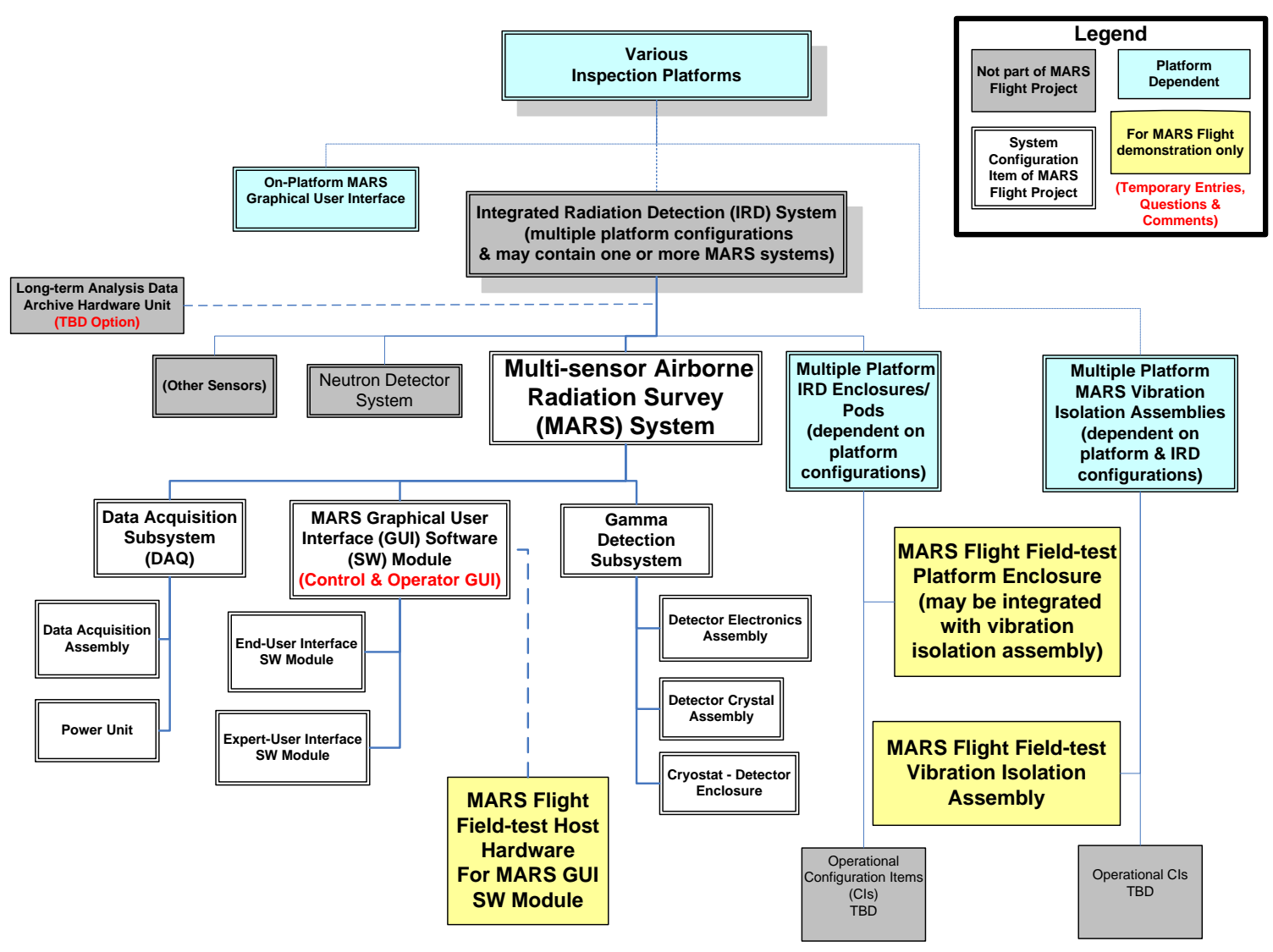

Figure 1: MARS Flight Engineering System Block Diagram.

\subsubsection{Detector Electronics Assembly}

The Detector Electronics Assembly, also referred to as the "saddle bags", mounts to the outside of the cryostat and houses preamplifiers and high voltage filters. All of the components are on hand and the first unit has been fully assembled. The second unit remains to be assembled and complete testing requires integration with the cryostat assembly.

\subsubsection{Detector Crystal Assembly}

The Detector Crystal Assembly, also known as the "spool assembly", houses the HPGe crystals and the Kapton flexible cable interconnect that carries high voltage to the detectors and the signals from the detectors out to the vacuum feedthroughs to the Detector Electronics Assembly. The flexible circuits have integrated front end electronics (FET, feedback resistor, test input capacitor) for each detector channel (Figure 2, Figure 3). The spool assemblies are completed and the flexible interconnects mounted, but the HPGe detectors are not yet installed (Figure 4). The spools have been fitted into the cryostat (Figure 5) and are undergoing vacuum processing (pump and bake) to reduce outgassing prior to introduction of the HPGe. 
PNNL-19096

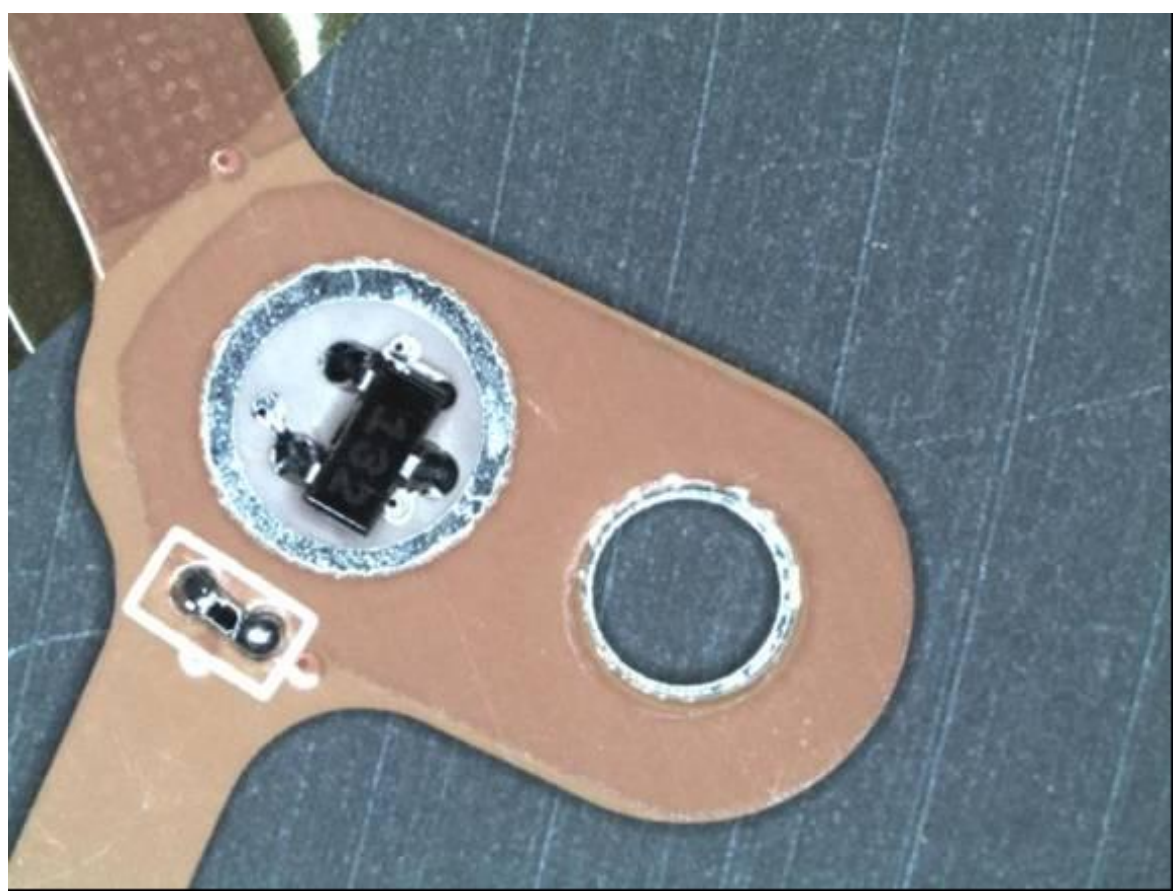

Figure 2: Detail of Front End circuit on flex cable. Component in circular area is the FET. Component to the below and to the right of the FET is the feedback resistor. Capacitors are built in to the circuit layout using the Kapton dielectric. The hole on the right is used to secure the flexible interconnect to the aluminum spool.

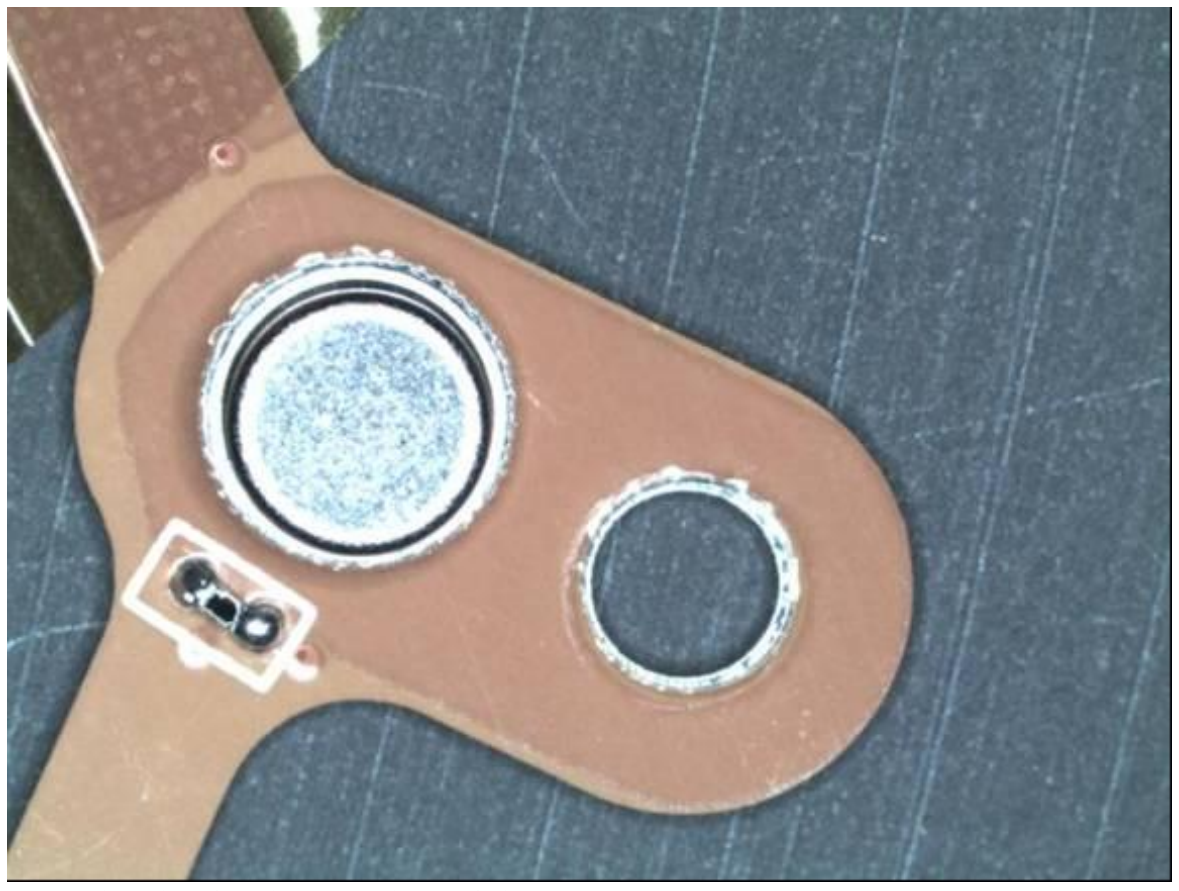

Figure 3: Front end circuit after installation of lid over FET. The lid encloses the warm ( 120-150 K) FET to prevent thermal radiation from hitting adjacent HPGe detectors that need to operate at $\leq 90 \mathrm{~K}$. 


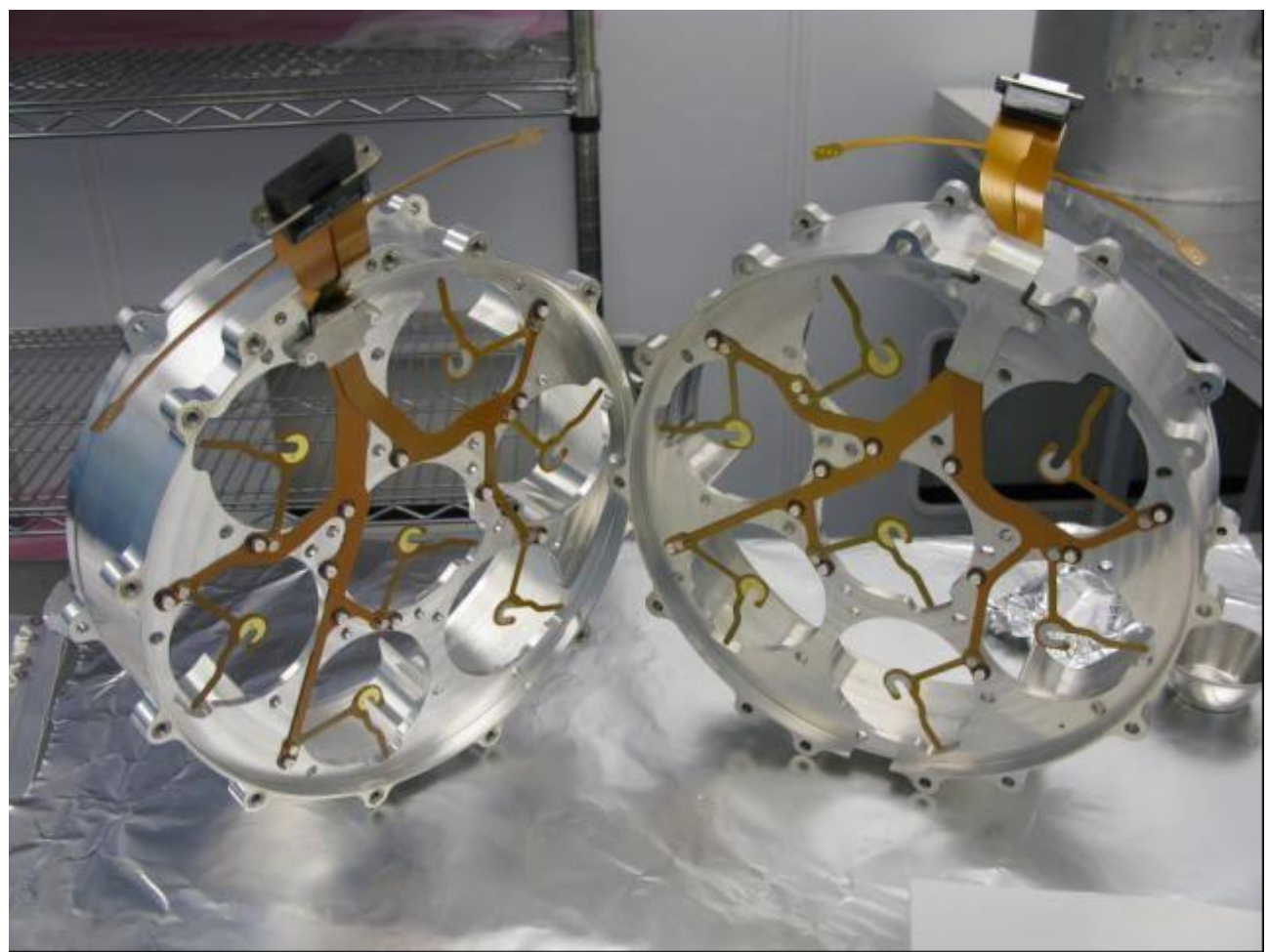

Figure 4: Spool assemblies with Kapton flexible interconnects installed.

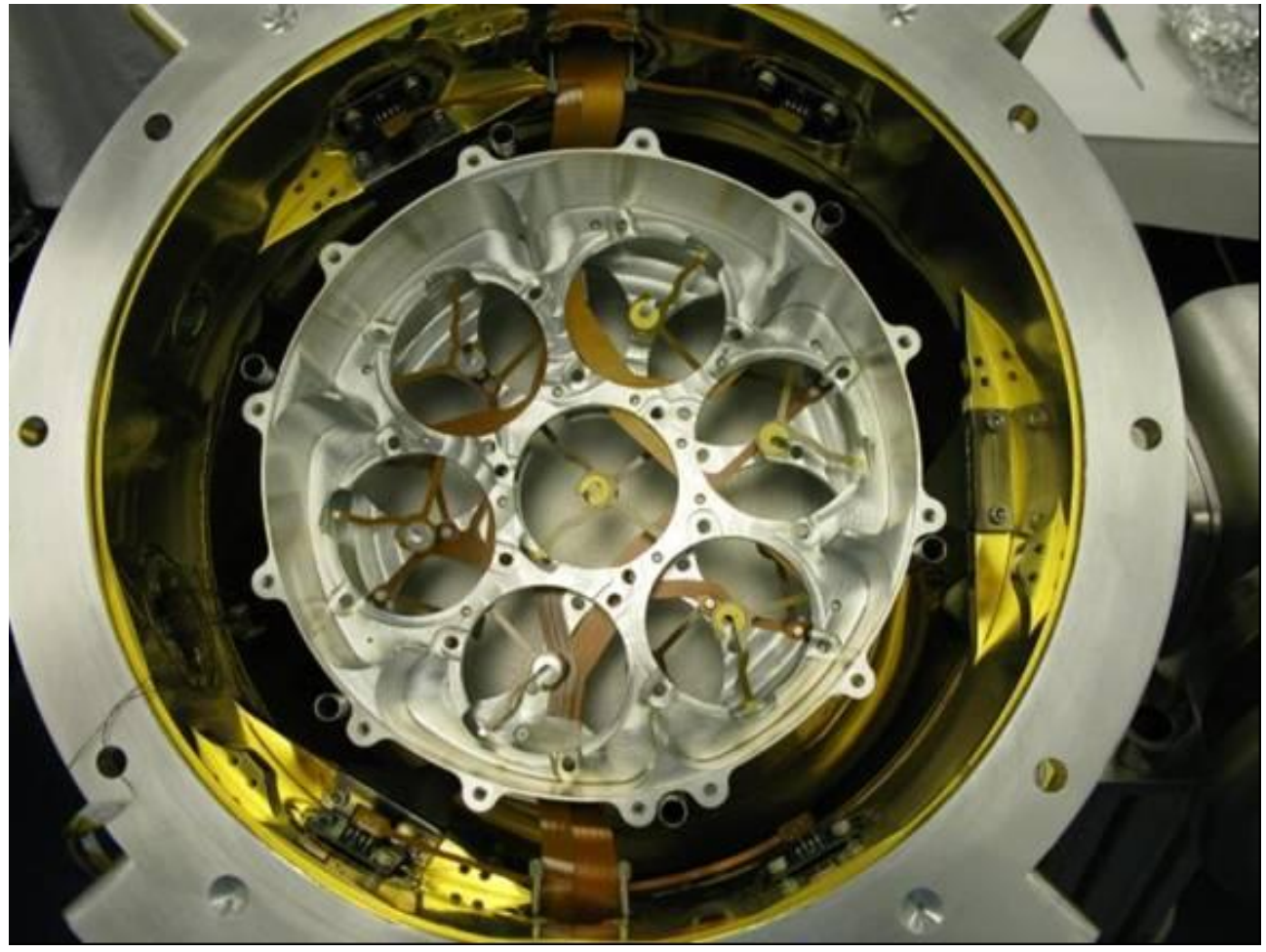

Figure 5: Detector Crystal Assembly mounted in Cryostat. 


\subsubsection{Cryostat - Detector Enclosure}

The HPGe detectors are operated at cryogenic temperatures $(\sim 90 \mathrm{~K})$ inside a vacuum cryostat. The assembly consists of the main vacuum vessel, a liquid nitrogen dewar, and a vacuum window. These parts were fabricated by Atlas Technologies in Port Townsend, WA who have unique capabilities in aluminum vacuum chamber manufacturing; including bi-metallic joints that enable them to join stainless steel conflate flanges to aluminum chambers. The main vacuum vessel is shown in Figure 6 during final vacuum testing at the vendor. The liquid nitrogen dewar is shown in Figure 7. The Dewar holds about 6 liters of liquid nitrogen and is omni-directional, i.e. the liquid will remain in the Dewar independent of the orientation of the assembly.

Heat transfer from the warm exterior walls of the cryostat to the liquid nitrogen cooled inner dewar and Detector Crystal Assembly is primarily from radiation. In order to minimize this heat transfer the warm surfaces are plated with very low emissivity gold (Epner Technologies, Inc. Lasergold). The plated cryostat is shown in Figure 8 and Figure 9. The thin, domed window is shown in Figure 10. It is designed to be minimal thickness for low-energy gamma ray sensitivity.

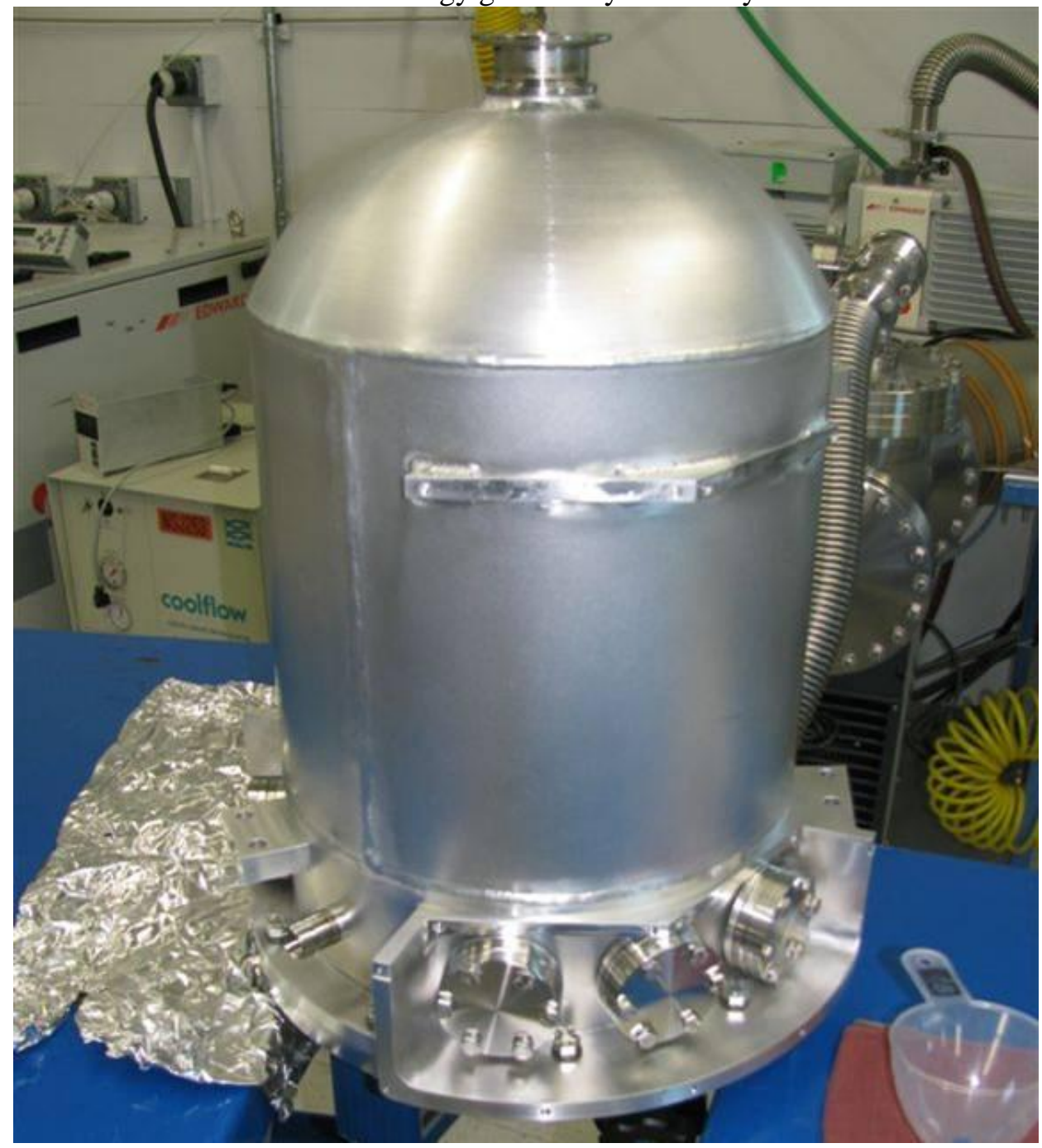

Figure 6: Vacuum cryostat prior to gold plating. 


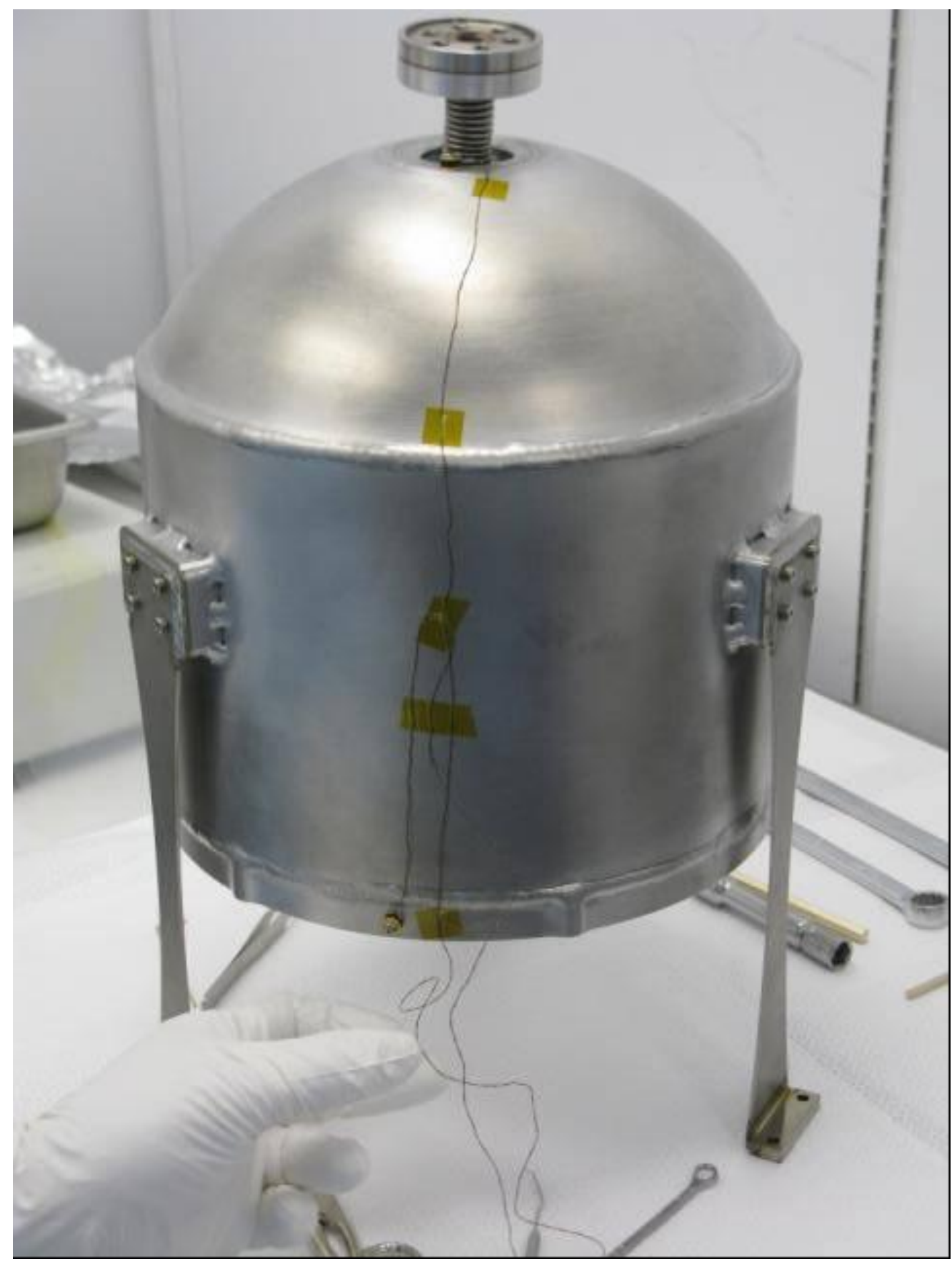

Figure 7: Liquid nitrogen Dewar. Bellows tube at top seals to top of cryostat and provides a fill port. Vertical legs are grade 5 Titanium supports that provide excellent mechanical strength with low thermal conductivity. Tank is being wired with silicon diode temperature sensors. 


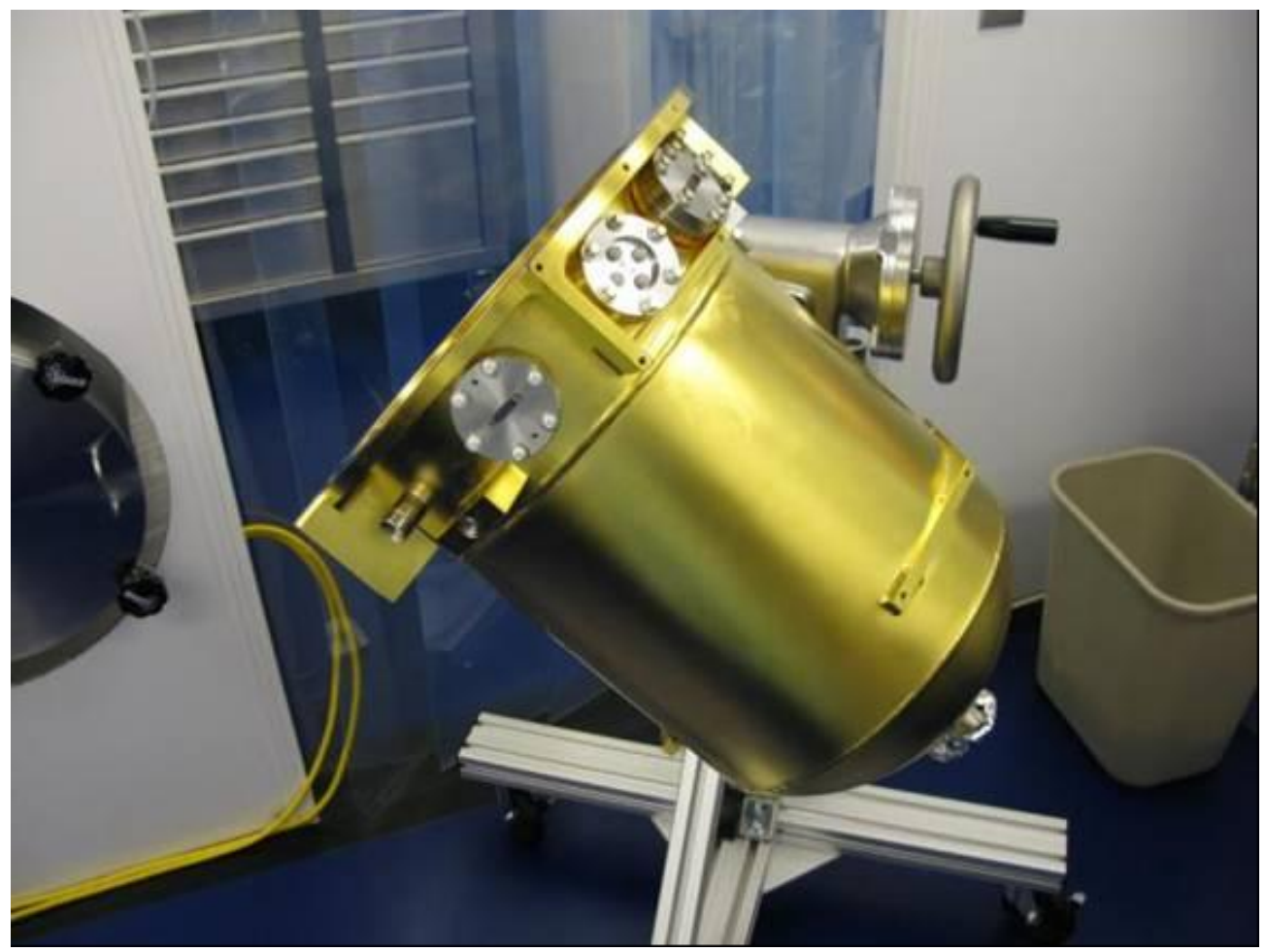

Figure 8: Cryostat after "Lasergold" plating. Several feedthroughs can be seen around the chamber (upper-right to lower-left): HPGe signal, high voltage, silicon diode temperature monitors, vacuum port.

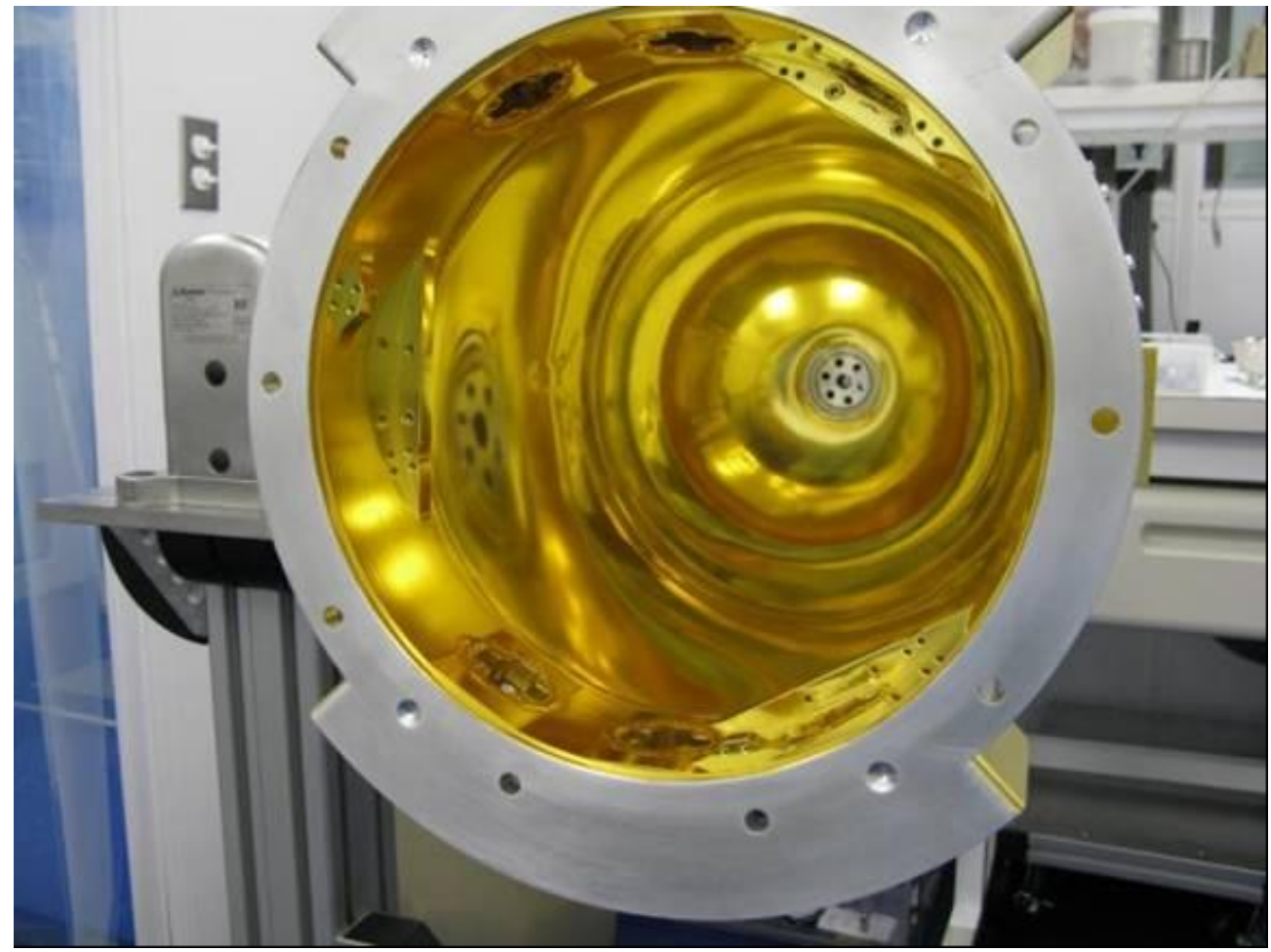

Figure 9: Interior of vacuum cryostat showing Lasergold plating. 


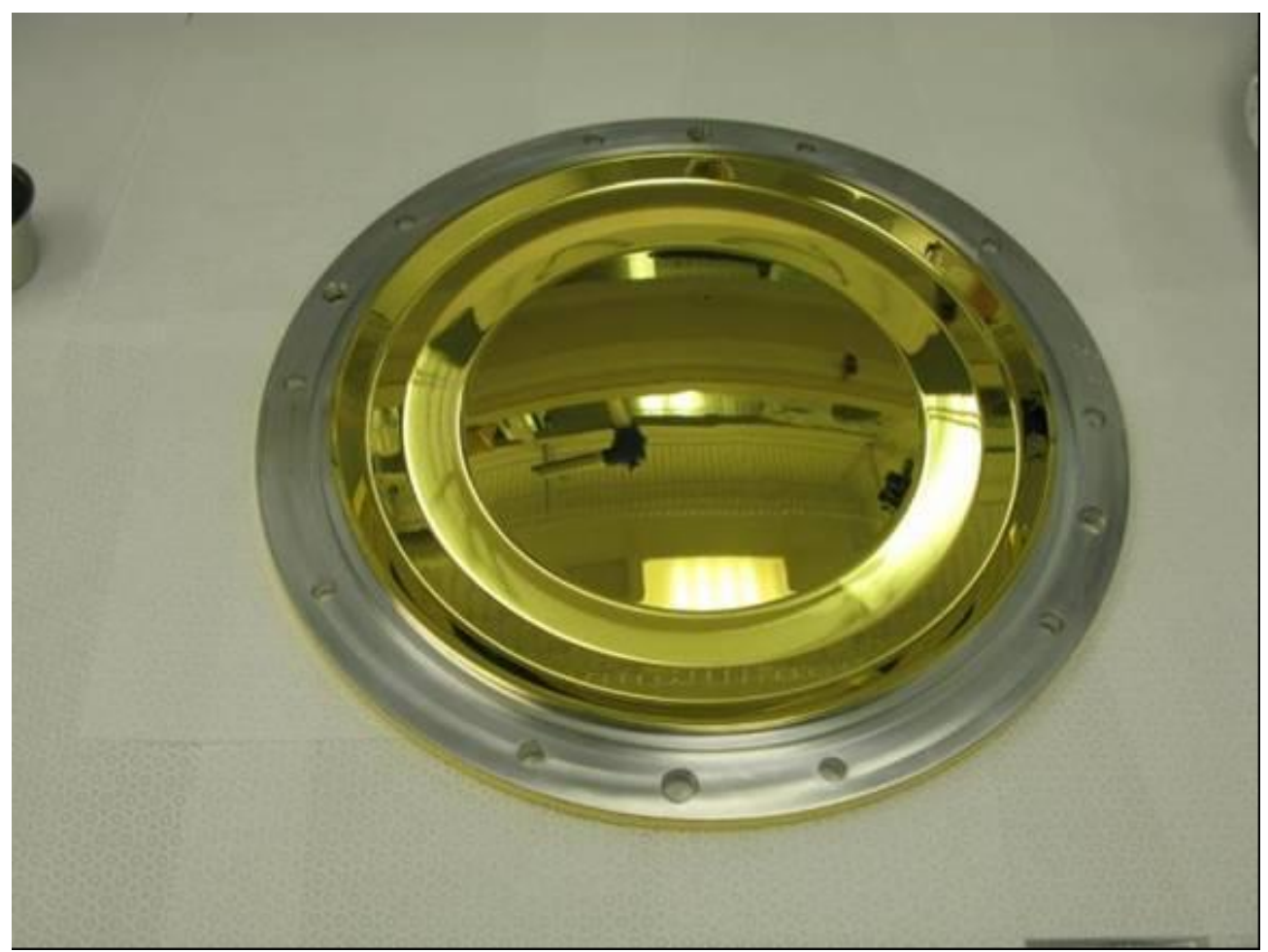

Figure 10: Thin domed window. This window is only $1 \mathrm{~mm}$ thick (aluminum) in order to maximize sensitivity to low energy gamma-rays for applications that require this sensitivity.

\subsection{Environmental Enclosure and Vibration Isolation Subsystem}

The environmental enclosure consists of a radome-type structure which encloses the MARS system and a support frame to house the associated electronics and support equipment. The environmental enclosure will be EMI shielded to provide a reduced RF environment for the MARS system to operate. It will also provide a thermally controlled environment for the system.

The MARS cryostat will be mounted in a vibration isolation framework. The framework and the coil spring isolators will absorb the majority of the shock and vibration of the Spartan platform. The cryostat mounted within the vibration isolation frame is shown in Figure 11.

The environmental enclosure and vibration isolation frame has been designed and is out for competitive bid. The environmental enclosure is shown mounted in the Spartan in Figure 12. 
PNNL-19096

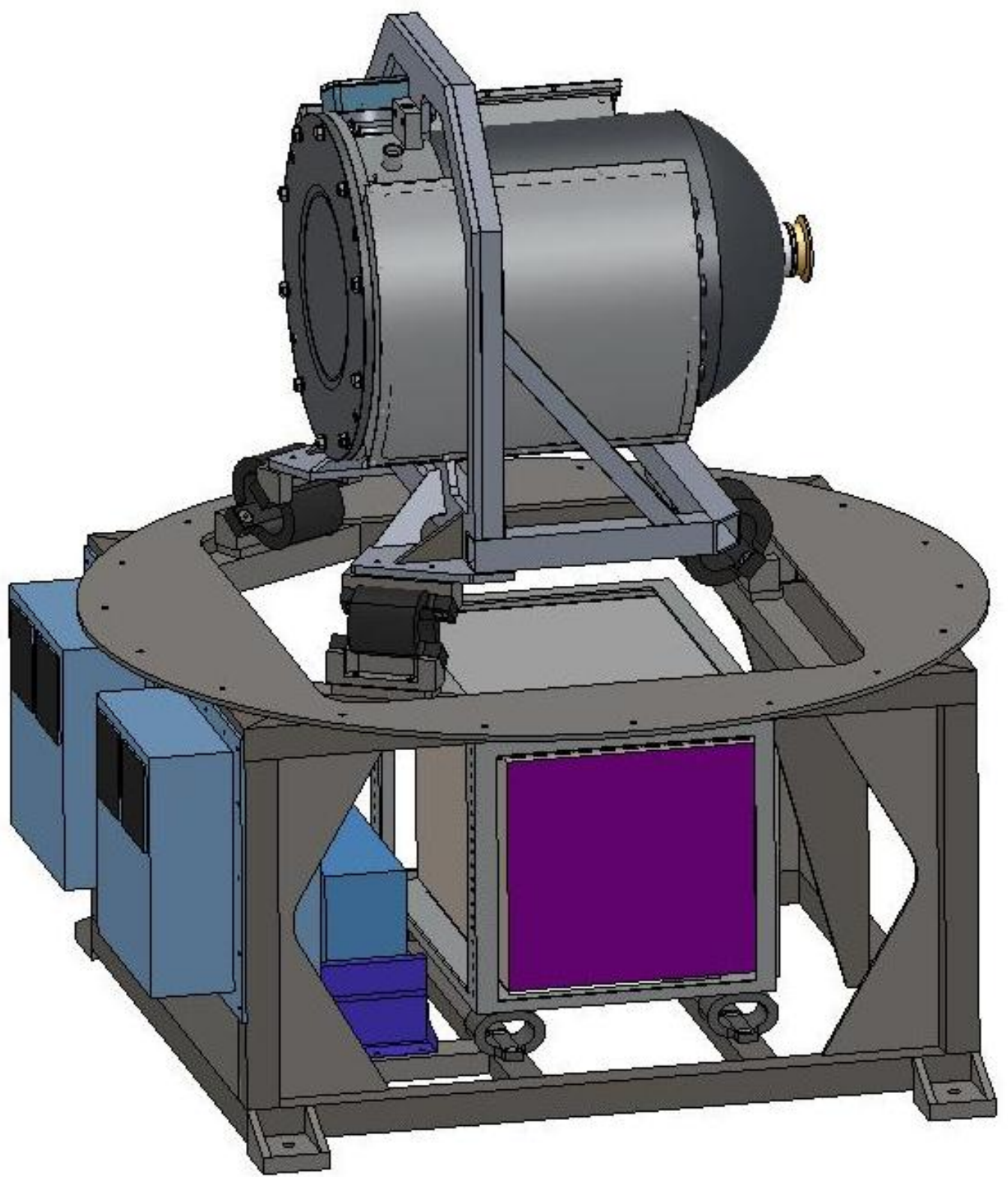

Figure 11: MARS vibration isolation and environmental enclosure without dome and side panels. 
PNNL-19096

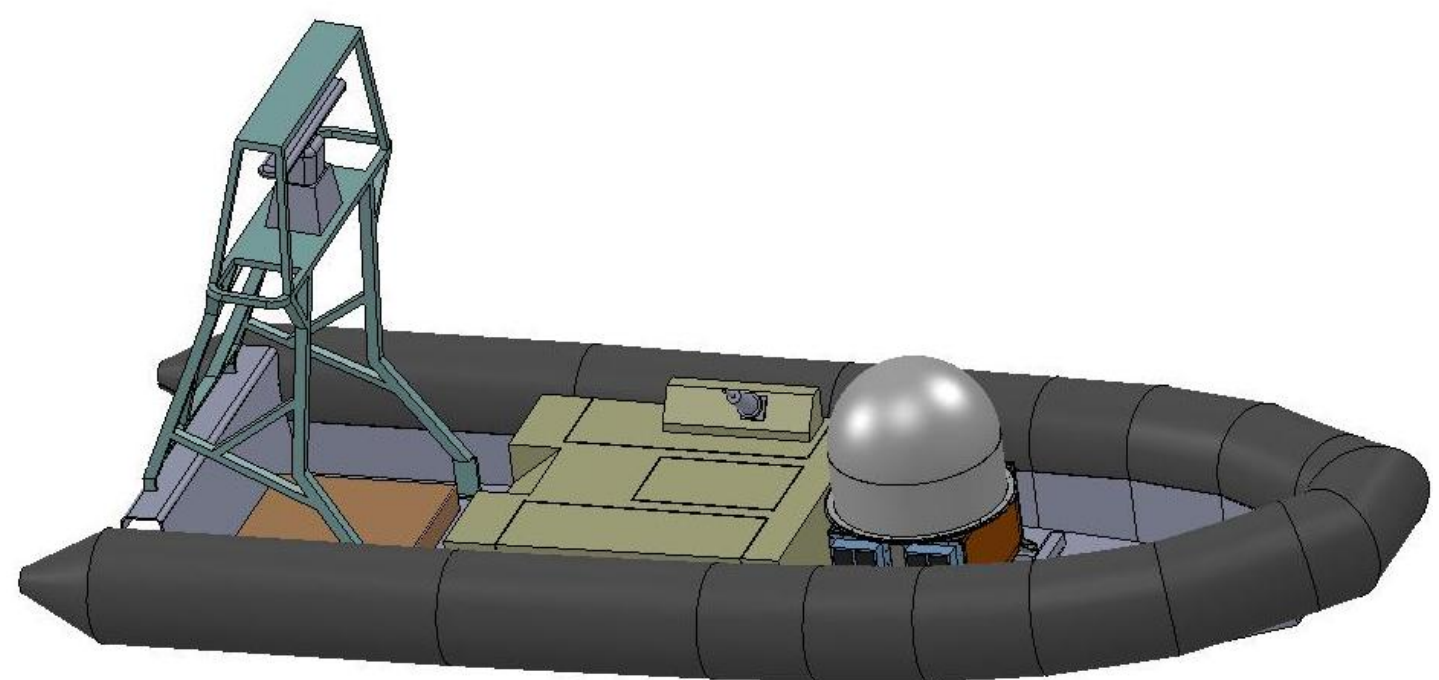

Figure 12: MARS system deployed in a Spartan watercraft

\subsection{Data Acquisition Subsystem}

The data acquisition system resides in a 19" wide $3 \mathrm{U}$ high compact-PCI chassis, shown in Figure 13. The system contains an embedded controller running Linux that controls the crate and runs the data acquisition and analysis software. Four 4-channel high voltage cards provide the bias voltage for the HPGe detectors. These are a PNNL design capable of operating up to $5 \mathrm{kV}$. The HPGe signals are processed using four PIXIE-4 multi-channel analyzer (MCA) boards from XIA, Inc that digitize the pulses from the detectors. These cards are configurable to store a variety of information from just the time-stamped pulse heights for normal operations up to the full digitized waveforms for debugging and development of advanced pulse shape analysis algorithms. The silicon diode temperature sensor signals are amplified on a signal conditioning board immediately outside the vacuum cryostat and then read out with a commercial data acquisition board in the c-PCI crate. The complete data acquisition system is assembled and has been tested using the MARS R\&D cryostat. The initial ruggedized c-PCI chassis had a backplane problem that prevented proper configuration of the PIXIE-4 cards (master-slave configuration). The crate was reworked by the vendor and has been successfully tested. Parts are on hand for two complete systems so that laboratory development and demonstration activities can occur concurrently. This also provides for a complete spare system for the demonstration activities (e.g. should there be an incident in shipping). 


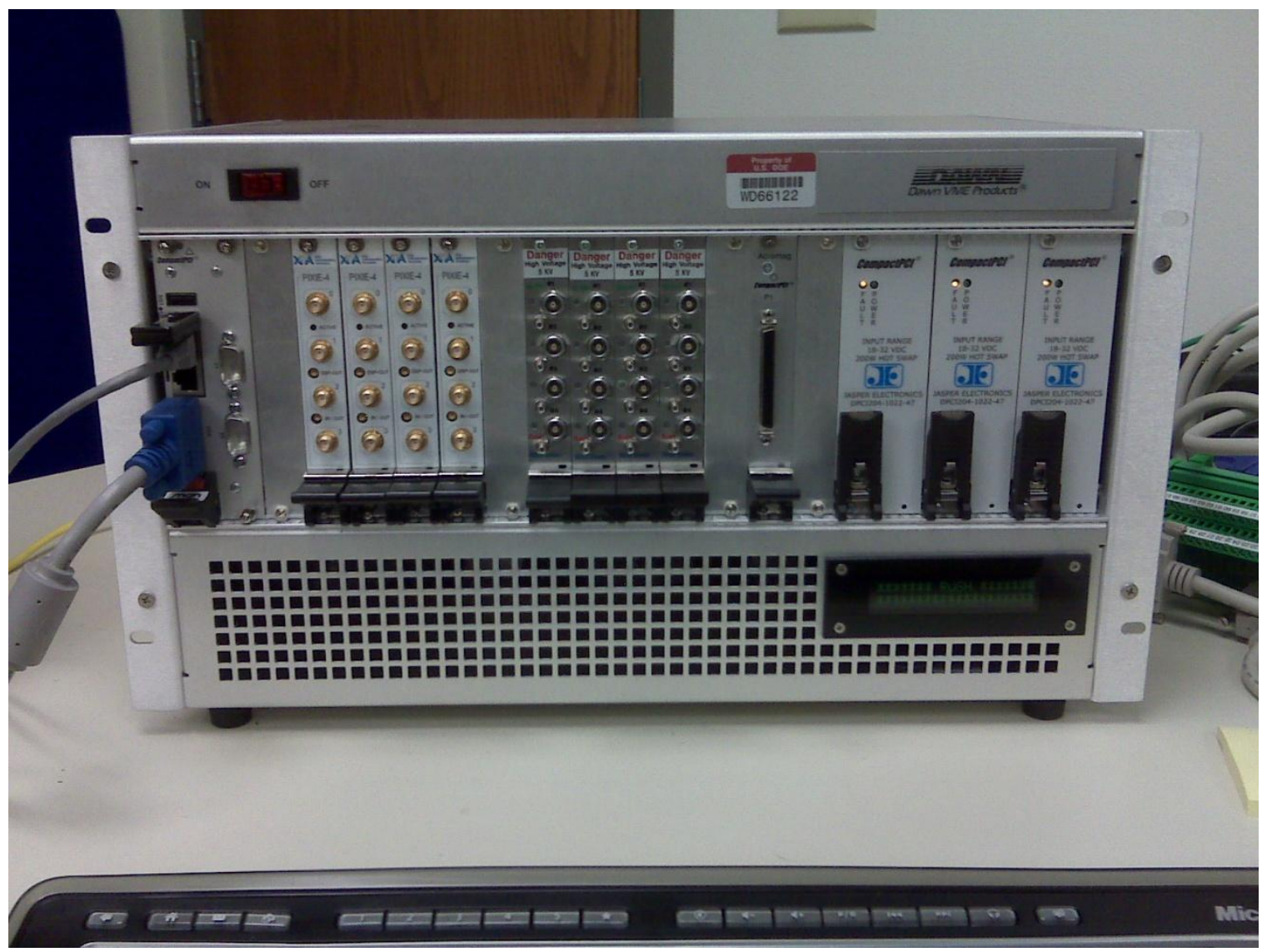

Figure 13: Compact PCI crate. This is the rugged crate from Dawn VME. The power supplies on the right are hot-swappable. The board next to the power supplies is the general purpose acquisition board that reads out the state-of-health data from silicon diode temperature sensors and feedback voltages from the preamplifiers. The four matching boards near the middle are the high voltage supplies for the HPGe detectors. The four matching boards towards the left are the MCA modules from XIA, Inc. The embedded processor and crate controller are located on the far left.

The data acquisition system also includes the operational software that runs on the embedded controller to collect and analyze the data. The basic data collection software is complete and tested. The analysis software is still under development, but most of the key elements are in place, including peak finding and fitting routines and semi-automated calibration routines. The main outstanding elements are isotope identification and alarming routines and advanced routines such as directionality or advanced characterization (e.g. Pu-600 code). The isotope ID and alarming routines will be built around welldeveloped algorithms that have been used for several projects at PNNL. Work is underway to develop directionality algorithms using data collected with the MARS R\&D detector. Additional analysis tools will be incorporated as time and budget permit.

\subsection{MARS Graphical User Interface (GUI) Software Module}

The MARS software consists of two aspects, the data collection and analysis software that reside in the embedded controller of the data acquisition system (server) and the GUI that the operator will use to interact with the system (client). The GUI can run either on the embedded computer or on a remote host platform. The GUI is Java based and can run under a variety of operating systems, including Windows and Unix/Linux systems. Data is passed from the server to the client via standard TCPIP protocol. 
The user interface is designed for a variety of user levels, including "basic" operators, "advanced" operators who would be familiar with gamma ray spectroscopy, and "system developers" who would configure and calibrate the system. The latter would be typical of a service depot operator in a deployed system. The user interface developed for the SPARTAN USV demonstration is shown in Figure 14. The upper left area provides red light/green light system status indicators. The graphic to the right of that shows an overhead view of the SPARTAN USV and an indicator of the direction of the detected radiation (implementation of an algorithm to provide this data is pending). The upper right area provides a list of alarms, including time, isotope, confidence level, type of source (medical, industrial, threat, etc.). The operator can select any alarm and bring up the gamma ray spectrum that triggered the alarm which will show the raw spectrum and overlays of the fitted peaks. The lower left area is a graph of radiation level (at the instrument) versus time; or the operator can toggle to view the current gamma ray spectra for any of several time intervals. The lower right area provides count rate versus time for specific isotopes. The isotopes presented in this region are user configurable.

Advanced user interfaces include control panels to adjust high voltage, monitor feedback voltages (related to detector leakage currents), turn individual channels on and off, etc. Other settings that configure the PIXIE-4 MCA boards are also available via these control panels. These settings include gain, decimation, threshold, coincidence masks etc.

The software is built with a flexible design allowing analysis algorithms to be added as further development occurs. The architecture allows for real-time user configuration of analysis routines without recompiling code.

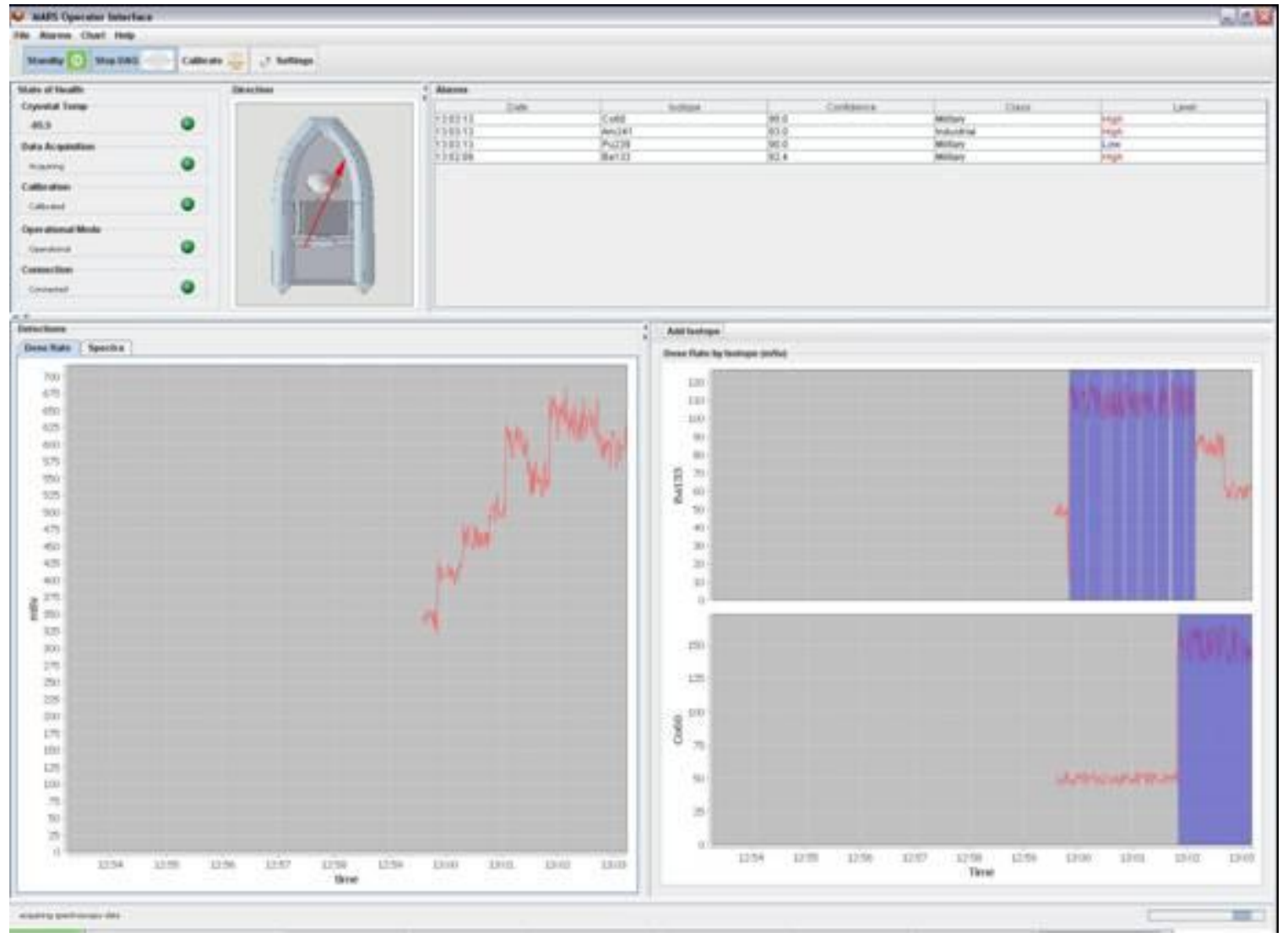

Figure 14: End user interface. 


\subsection{Summary}

The MARS Flight Engineering project is developing a field demonstration unit as a second spiral development of the MARS Technology. An initial laboratory prototype system was designed, built and tested under the MARS R\&D project. This second spiral includes modifications to the design based on lessons learned in the laboratory prototype, additional engineering analysis, and focus on a specific deployment platform - the SPARTAN unmanned surface vehicle, a rigid hull inflatable watercraft. Significant emphasis has been placed on developing a graphical user interface suitable for the target enduser skill sets. Both the hardware and software are progressing well and are on track for the field demonstration in May, 2010. 


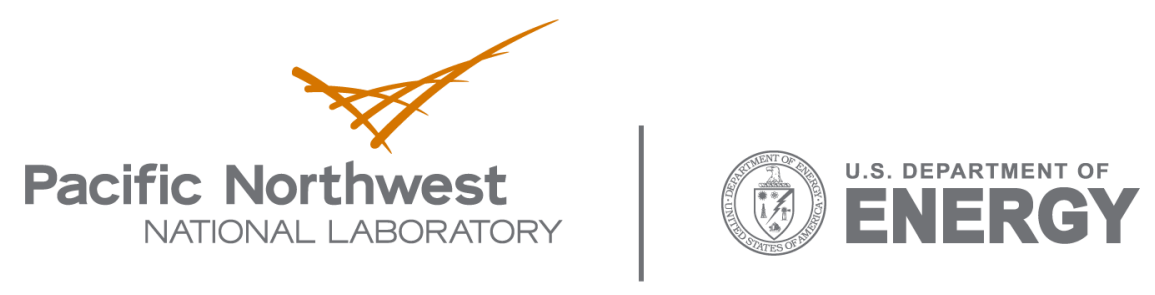

902 Battelle Boulevard

P.O. Box 999

Richland, WA 99352

1-888-375-PNNL (7665)

www.pnl.gov 